\title{
Combining Thyroidectomy with Cardiac Surgery: Implications for the Endocrine Surgeon
}

\author{
Sudin Varghese Daniel, Mark Reginald Lansdown
}

\section{ABSTRACT}

The management of incidentally detected retrosternal goiter in patients with cardiac disease awaiting open heart surgery is controversial. Here, we present the case of a 79-year-old man; who had coronary artery bypass grafting, aortic valve replacement and thyroidectomy for retrosternal goiter under a single anesthetic. A literature search was conducted to study patient demographics, thyroid symptomatology, pathology, complications and the risks and benefits of the combined procedures. Literature search revealed only a few similar cases of a combined surgical approach and these are from the perspective of the cardiac surgeon. The study is presented to highlight the implications of such combined procedures for the endocrine surgeon.

A medline search was conducted for combined procedures on heart and thyroid. Five case reports and two reviews, including one case of off-pump coronary artery bypass grafting (CABG) was obtained. The mean age of the patients was 69 years (range, 55-79). Retrosternal goiter was the commonest indication $(67 \%)$, half of them presenting with tracheal compression. Thyrotoxicosis was observed in $22 \%$. Beinign multinodular goiter was the commonest pathology (89\%). There was one case of Grave's disease. There were no reported malignancies. There were no reported complications from the endocrine surgery.

The various cardiac procedures in the combined operations were coronary artery bypass grafting, aortic valve replacement, mitral valve replacement, a combination of these and a case of closure of atrial septal defect.

The review has looked into the anatomical and physiological implications of combined operations, operative risks and has upheld the safety of such combined procedures.

Keywords: Thyroidectomy, Coronary artery bypass grafting, Aortic valve replacement, Retrosternal goiter.

How to cite this article: Daniel SV, Lansdown MR. Combining Thyroidectomy with Cardiac Surgery: Implications for the Endocrine Surgeon. World J Endoc Surg 2012;4(2):43-46.

Source of support: Nil

Conflict of interest: None

\section{CASE REPORT}

A 69-year-old Caucasian man presented to the cardiologist with increasing shortness of breath on exertion of 18 months duration. His exercise tolerance was about 25 yards. He had angina for over 14 years and was an ex smoker. His angina was classified as CCS2 (slight limitation of ordinary activity) and dyspnea of NYHA 3 (marked limitation of physical activity). Coronary angiography demonstrated significant stenosis of the right coronary artery and of a large obtuse marginal branch. Echocardiography showed an aortic valve gradient of $70 \mathrm{~mm} \mathrm{Hg}$, with good left ventricular function. He was offered coronary artery bypass grafting (CABG) and aortic valve replacement (AVR).

During preoperative work-up, chest X-ray showed a mediastinal mass on the right side pushing the trachea to the left. A subsequent computed tomography (CT) scan confirmed a retrosternal goiter arising from the right lobe of thyroid within the superior mediastinum measuring $4.5 \times 5 \times 5.5 \mathrm{~cm}$ (Fig. 1). This was pushing the trachea to the left without significant tracheal compression. The upper part of the thyroid mass was just palpable in the neck. Thyroid function tests were normal and he was clinically euthyroid. An Endocrine surgeon was involved early. Clinically and radiologically, the patient had an asymmetric multinodular goiter affecting predominantly the right lobe with minimal changes on the left. The need for thyroidectomy was discussed with the patient. A combined procedure was planned as although sternotomy can be avoided in the vast majority of patients with a retrosternal goiter; in this patient there was little thyroid actually in the neck. Therefore, postponing the thyroidectomy to a later date would risk a second sternotomy which would be difficult due to scarring. After discussion of the risks and benefits, a decision was made with the patient and cardiac surgeon that removing the right lobe of the thyroid at the time of open heart surgery was a sensible option.

The patient was prepared and consented for right thyroid lobectomy, and CABG with AVR. Through a median

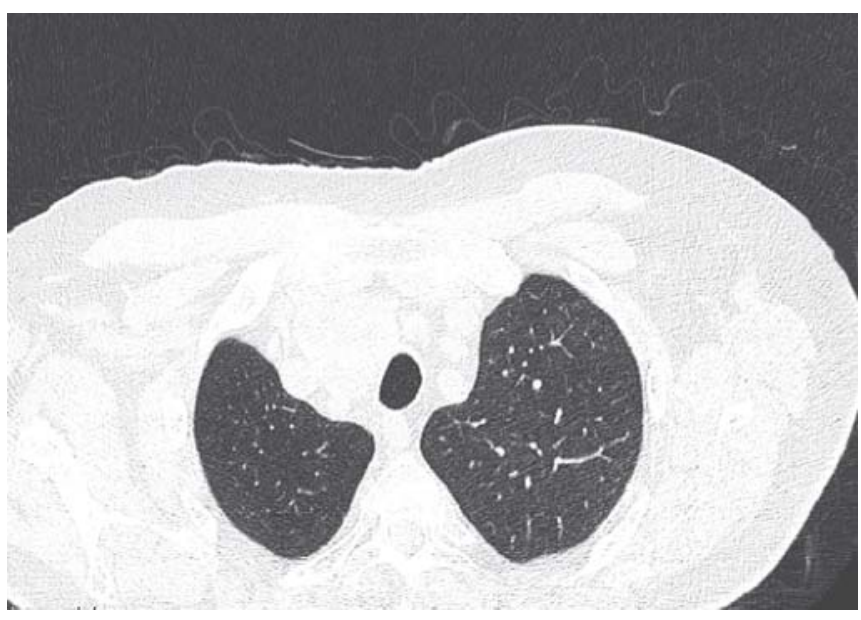

Fig. 1: Retrosternal goiter displacing trachea 
sternotomy he had CABG to obtuse marginal artery and right coronary artery using long saphenous vein grafts. AVR was done with a tissue valve (Medtronic Hall ${ }^{\mathrm{TM}}$ Valve). After the cardiac surgery, the endocrine surgeon performed the right thyroid lobectomy through a cervical collar incision in continuity with the sternotomy incision. Both parathyroid glands were identified on the right side and preserved. The recurrent laryngeal nerve was identified on the right side and safeguarded. The left lobe was not disturbed. A drain was not left in the thyroid bed as this was in continuity with the mediastinum into which a drain was placed routinely after cardiac operation. The patient was on cardiopulmonary bypass for 135 minutes and the whole operation took about 270 minutes. The patient was ventilated for 7 hours postoperatively and spent one day in the intensive care unit. He required no ionotropes or vasoconstrictors in the postoperative period. There were no immediate complications from the thyroidectomy. The patient made a good recovery and was discharged home on the ninth postoperative day. The histopathology of the thyroid lobe showed it to be multinodular goiter with no evidence of neoplasia. He remained euthyroid and was doing well at review at 6 weeks. He was discharged from regular followup in the endocrine surgery clinic.

\section{LITERATURE REVIEW}

There are few published reports on combined procedures on the heart and thyroid suggesting this combination of procedures is uncommon. This review was done to outline the implications of such combined procedures for the endocrine surgeon.

\section{AIM}

To study patient demographics, thyroid symptomatology, pathology, complications and the risks and benefits of the combined procedures.

\section{MATERIALS AND METHODS}

A medline search was undertaken for combined procedures on heart and thyroid. This yielded only five case reports and two reviews. Most of the reports emphasized the cardiac side of the combined procedure. This included one case of off-pump CABG.

\section{DISCUSSION}

There were nine combined procedures including our case report (Table 1). ${ }^{1-6}$ Patient age ranged from 55 to 79, with a mean age of 69 years. Five patients were males and four females. Two were asymptomatic. Thyrotoxicosis was seen in $22 \%(2 / 9)$ patients. The majority of the patients were euthyroid (7/9). The reason for thyroidectomy was retrosternal goiter in 67\% (6/9) patients. Three of them had symptoms of tracheal compression. A total of $89 \%$ (8/9) patients had a pathological diagnosis of MNG, one being toxic. There was one case of Grave's disease. No malignancies were reported. There were no reported complications from the endocrine surgery (hypocalcemia,

\begin{tabular}{|c|c|c|c|c|c|c|c|c|c|}
\hline Authors & Age & Sex & $\begin{array}{l}\text { Thyroid } \\
\text { disorder }\end{array}$ & symptoms & $\begin{array}{l}\text { Endocrine } \\
\text { function }\end{array}$ & $\begin{array}{l}\text { Surgery } \\
\text { done }\end{array}$ & $\begin{array}{l}\text { Pathology } \\
\text { of thyroid }\end{array}$ & $\begin{array}{l}\text { Cardiac } \\
\text { procedure }\end{array}$ & Outcome \\
\hline $\begin{array}{l}\text { Present } \\
\text { study }\end{array}$ & 79 & $M$ & RG & Asymptomatic & Euthyroid & $\begin{array}{l}\text { Thyroid } \\
\text { lobectomy }\end{array}$ & MNG & $\begin{array}{l}\text { CABG, } \\
\text { AVR }\end{array}$ & Good \\
\hline $\begin{array}{l}\text { Tang G } \\
\mathrm{H} \text { L et } \mathrm{al}^{1}\end{array}$ & 67 & M & RG & Asymptomatic & Euthyroid & STT & MNG & $\begin{array}{l}\text { CABG, } \\
\text { AVR }\end{array}$ & Good \\
\hline $\begin{array}{l}\text { Litmathe J } \\
\text { et } \mathrm{al}^{2}\end{array}$ & 67 & M & Goiter & - & Euthyroid & Thyroidectomy & MNG & CABG & Good \\
\hline $\begin{array}{l}\text { Litmathe J } \\
\text { et } \mathrm{al}^{2}\end{array}$ & 65 & M & RG & - & Euthyroid & Thyroidectomy & MNG & CABG & Died \\
\hline $\begin{array}{l}\text { Litmathe J } \\
\text { et } \mathrm{al}^{2}\end{array}$ & 78 & M & Goiter & - & Euthyroid & Thyroidectomy & MNG & AVR & Good \\
\hline $\begin{array}{l}\text { Demirag MK } \\
\text { et } \mathrm{al}^{3}\end{array}$ & 55 & $\mathrm{~F}$ & RG & $\begin{array}{l}\text { Hyperthyroidism, } \\
\text { tracheal } \\
\text { compression }\end{array}$ & Hyperthyroidism & $\mathrm{TT}$ & Toxic MNG & ASD repair & Good \\
\hline $\begin{array}{l}\text { Matsuyama K } \\
\text { et al }{ }^{4}\end{array}$ & 65 & $\mathrm{~F}$ & Grave's & $\begin{array}{l}\text { Treated for } \\
\text { thyrotoxicosis }\end{array}$ & Hyperthyroid & TT & Grave's & CABG, AVR & Good \\
\hline $\begin{array}{l}\text { Mehra AP } \\
\text { et } \mathrm{al}^{5}\end{array}$ & 70 & $\mathrm{~F}$ & RG & $\begin{array}{l}\text { Tracheal } \\
\text { compression }\end{array}$ & Euthyroid & $\mathrm{TT}$ & MNG & CABG & Good \\
\hline $\begin{array}{l}\text { Wexler S } \\
\text { et } \mathrm{al}^{6}\end{array}$ & 76 & $\mathrm{~F}$ & RG & $\begin{array}{l}\text { Tracheal } \\
\text { compression }\end{array}$ & Euthyroid & $\mathrm{TT}$ & MNG & CABG & Good \\
\hline
\end{tabular}

MNG: Multinodular goiter; RG: Retrosternal goiter; TT: Total thyroidectomy; ASD: Atrial septal defect 
evidence of recurrent laryngeal nerve injury or postoperative bleeding). The various cardiac operations included coronary artery bypass grafting, aortic valve replacement, mitral valve replacement, a combination of these and closure of an atrial septal defect.

\section{RATIONALE FOR COMBINING CARDIAC SURGERY WITH RETROSTERNAL GOITER REQUIRING THYROIDECTOMY}

In our case, an asymptomatic retrosternal goiter was found incidentally during preoperative evaluation for CABG and AVR. Retrosternal goiter is defined as one where more than or equal to $50 \%$ of the thyroid mass is located in the mediastinum. ${ }^{7,8}$ There was time to investigate the thyroid in this case but it was not feasible to offer a substantial period of observation to determine whether or not the gland was stable or growing. Although not every retrosternal goiter requires surgery, they are sometimes malignant, (3 to $16 \%$ ). ${ }^{9-11}$ They are also prone to complications, such as hemorrhage into the gland causing acute airway compromise. Combining such cases of thyroidectomy with cardiac surgery is sensible due to the anatomic relations of the gland with the mediastinal cavity. Although the vast majority of retrosternal goiters can be removed through a cervical incision, it is sometimes necessary to do a sternotomy or at least a manubriotomy. Preoperative estimation of thyroid volume by CT could predict the ones requiring sternotomy..$^{12}$ Sternotomy is most likely to be required if the retrosternal part is large and there is little thyroid in the neck, if invasive cancer is present or suspected, goiter is ectopic, or if there is CT evidence of adherence to surrounding mediastinal structures and extension of the goiter below the arch of aorta. ${ }^{13}$ Rugiu MG et al in his cohort of 53 retrosternal goiters states that previous thyroid surgery in the neck does not correlate with need for sternotomy as sometimes thought. ${ }^{12}$ Sternotomy after cardiac surgery is difficult due to scarring. Coronary bypass grafts are at risk of damage and reischemia at second sternotomy. ${ }^{14}$ For these reasons, patients for cardiac surgery, who may benefit from thyroid surgery for retrosternal goiter, should be given the opportunity to discuss the merits of a single stage procedure.

\section{THYROID ENDOCRINE DYSFUNCTION AND ITS EFFECTS IN PATIENTS WITH CARDIAC DISEASES}

Thyroid disease occurs with a frequency of about $11 \%$ in patients with valvular or coronary artery disease. ${ }^{15}$ Thyroid dysfunction affects cardiovascular physiology by influencing heart rate, stroke volume and peripheral arteriolar reactivity. Hyperthyrodism on the one hand predisposes to supraventricular tachyarrhythmias and increases myocardial oxygen consumption. Hypothyrodism on the other hand reduces cardiac output and increases peripheral vascular resistance. ${ }^{16}$ Cardiopulmonary bypass is known to induce acute hypothyroidism in the immediate postoperative period as evidenced by reduced T3 (triiodothyronine) levels (euthyroid sick syndrome). This is as a result of inhibition of peripheral deiodination of T4 (Thyroixine) to T3 (Triiodothyronine) ${ }^{17}$ Moderate hypothyroid status does not increase the risks associated with cardiac surgery and is not a contraindication for CABG. ${ }^{18}$ Cumulative risk of the combined surgery seems to be less than a two stage procedure. ${ }^{4}$ Amiodarone, the class III antiarrhythmic drug is associated with thyroid dysfunction. Due to its high iodine content, it can cause mild derangements, overt hypothyroidism or even thyrotoxicosis. This should be borne in mind when treating patients with combined cardiac and thyroid disorder especially in the periopertive setting. ${ }^{19}$

\section{ARE WE MORE LIKELY TO INJURE THE RECURRENT LARYNGEAL NERVE IN COMBINED OPERATIONS?}

Recurrent laryngeal nerve injury being a well-known complication of thyroidectomy, has to be considered in the setting of a combined surgery where sternotomy and manipulations on the heart have the potential to put the nerve at risk. Incidence of upto 5\% temporary vocal cord palsy and $1.4 \%$ permanent damage has been reported following thyroidectomy. ${ }^{20}$ Open heart surgery itself can predispose to recurrent laryngeal nerve injury. A total of 1 to $2 \%$ incidence has been reported from various studies. Central venous catheterization, traumatic endotracheal intubation, esophageal traction, median sternotomy, sternal traction and manipulation of the heart during open heart procedures are all reported to put the recurrent laryngeal nerve at risk. ${ }^{21}$ Thyroid surgeons should, therefore, be extra careful as the risk of damaging the recurrent laryngeal nerve is higher during combined procedures.

\section{CONCLUSION}

Due to the increased risk of bleeding, all except three cases including the above report had thyroidectomy performed before patient was heparinized for the cardiopulmonary bypass. However, in those patients who had thyroidectomy following the bypass, increased postoperative bleeding was not reported. Meticulous attention to hemostasis appears to be the key to prevent postoperative hemorrhagic complications from thyroidectomy. Timing of thyroidectomy in a combined operation, therefore, may not 
significantly influence the final outcome, although it seems reasonable to stabilize the heart before interventions on the thyroid. An exception may be thyroidectomy for Grave's disease where removing the thyroid before the cardiac surgery could help prevent postoperative tachyarrhythmias which could otherwise be precipitated during thyroidectomy. No recurrent laryngeal nerve injury or hypocalcemia was reported. Combining thyroid surgery with open heart surgery did not increase the risk to the patient. On the contrary, combined procedures avoid the need for a second stage operation for thyroid surgery which is difficult if sternotomy is required in retrosternal goiter. It also helps prevent damage to bypass grafts which could otherwise be damaged at a second stage procedure involving sternotomy. The review, therefore, has upheld the safety, surgical feasibility and the logic behind the combined procedure. Therefore, patients with asymptomatic or symptomatic goiters who are planned for cardiac surgery, should be referred to endocrine surgeons for thyroidectomy as a single stage procedure whenever indicated, rather than embarking on thyroidectomy as a second stage procedure. Even in asymptomatic goiters, especially retrosternal goiters, patients should be counseled about the benefits of having a single stage procedure. These calls for good interdepartmental cooperation and the role of the cardiac surgeon in such cases cannot be over emphasized.

\section{REFERENCES}

1. Tang GHL, Feindel CM, Gullane PJ, Butany J. Combined cardiac surgery and excision of a retrosternal thyroid mass. A case report. J Card Surg 2006;21:281-83.

2. Litmathe J, Kurt M, Boeken U, Roehrborn A, Feindt P, Gams E. Combined cardiothoracic surgery and interventions of the para/thyroid gland. A rare clinical cooperation. Z Kardiol 2004;94:28-32.

3. Demirag MK, Topgul K, Sarac A, Keceligil HT. Atrial setpal defect and retrosternal goitre operated in the same session: A case report. Ann Thorac Cardiovasc Surg 2007;13:272-74.

4. Matsuyama K, UedaY, Ogino H, Sugita T, Nishizawa J, Matsubayashi K, et al. Combined cardiac surgery and total thyroidectomy: A case report. Jpn Circ J 1999;63:1004-06.

5. Mehra AP, Shah KS, Jain PC, Bhansali SK, Sunawala JD, Gandhi BV, Oswal A. Combined off-pump coronary artery bypass grafting and thyroidectomy. Ann Thorac Surg 2009;88: 661-63.
6. Wexler S, Yamane K, Fisher KW, Diehl JT, Hirose H. Singlestage operation for giant substernal goiter with severe coronary artery disease. Ann Thorac Cardiovasc Surg 2011 July;13.

7. De Souza FM, Smith PE. Retrosternal goiter. J Otolaryngol 1983;12:393-96.

8. Katlic MR, Wang CA, Grillo HC. Substernal goiter. Ann Thorac Surg 1985;39:391-99.

9. Rigiu MG, Piemonte M. Surgical approach to retrosternal goitre; do we still need sternotomy? 2009;29:331-38.

10. Allo MD, Thompson NW. Rationale for the operative management of substernal goiters. Surgery 1983;94:969-77.

11. Torre G, Borgonovo G, Amato A, et al. Surgical management of substernal goiter: Analysis of 237 patients. Am Surg 1995;61: 826-31.

12. Rugiu MG, Piemonte M. Acta Otorhinolaryngol Ital 2009;29: 331-38.

13. Cohen JP. Substernal goiters and sternotomy. Laryngoscope 2009;119:683-88.

14. Mehta Y, Sujatha P, Juneja R, et al. OPCAB and thyroidectomy in a patient with a severely compromised airway. J Cardiothorac Vasc Anaesth 2005;19:79-82.

15. Jones TH, Hunter SM, Price A, Angelini GD. Should thyroid functions be assessed before cardiopulmonary bypass operations? Ann Thorac Surg 1994;58:434-36.

16. Fazio S, Palmieri EA, Lombardi G, Biondi Bernadette. Effects of thyroid hormone on the cardiovascular system. Recent Prog Horm Res 2004;59:31-50.

17. Clark RE. Cardiopulmonary bypass and thyroid hormone metabolism. Ann Thorac Surg 1993;56:S35-S42.

18. Drucker DJ, Burrow GN. Cardiovascular surgery in the hypothyroid patient. Arch Intern Med 1985;145:1585-87.

19. Padmanabhan H. Amiodarone and thyroid dysfunction. South Med J 2010;103:922-30.

20. Lo C, Kwok K, Yuen P. A prospective evaluation of recurrent laryngeal nerve paralysis during thyroidectomy. Arch Surg 2000;135:204-07.

21. Hamdan AL, Moukarbel RV, Farhat F, Obeid M. Vocal cord paralysis after open heart surgery. Eur J Cardiothorac Surg 2002;21:671-74.

\section{ABOUT THE AUTHORS}

\section{Sudin Varghese Daniel (Corresponding Author)}

Registrar, Department of Breast and Endocrine, Leeds Teaching Hospitals, Yorkshire, United Kingdom, e-mail: sudinvd@hotmail.com

\section{Mark Reginald Lansdown}

Consultant, Department of Breast and Endocrine, Leeds Teaching Hospitals, Yorkshire, United Kingdom 